\title{
Evaluating the Human Resource Management Practices Effectiveness and Providing a Comprehensive Model (The Case of Nir Pars Company)
}

\author{
Davood Ghiyasvand \\ Corresponding Author, M.S. Candidate of Master Business Administration (MBA) \\ Isfahan Science and Research branch, Islamic Azad University, Isfahan, Iran \\ Hadi Teimouri \\ Assistant Professor, Management Department, University of Isfahan, Isfahan, Iran \\ Reza Ansari \\ Assistant Professor, Management Department, University of Isfahan, Isfahan, Iran \\ Accepted: August 03, 2013 Published: Sep 14, 2013 \\ Doi:10.5296/ijhrs.v3i3.4272 URL: http://dx.doi.org/10.5296/ijhrs.v3i3.4272
}

\begin{abstract}
Nowadays, as organizations advance towards development and progress, the need for efficient labor will be more noticeable. In such circumstances, the success of organizations in economic, cultural, social and governmental interactions is due to competence and effectiveness of Human resources and in fact human resources are the major assistance in achieving organizational goals and improving performance.

The purpose of this article is to explore the level of business intelligence and propose a comprehensive model for Nir Pars Company in Tehran. This is an applied, descriptivecorrelation research, conducted by survey methodology. A collection of 400 experts and managers of different organizational levels of Nir Pars Company were the statistical population of the study and a batch of 225 persons were chosen by simple random sampling as the research sample. Library method was used for data collection to form the theoretical foundations of the research, and we used our own questionnaire to confirm or refute the research hypotheses; which has the required reliability and validity (Cronbach's alpha coefficient of 0.961). To explore the relationships between the elements of the Model, factor analysis and structural equation modeling techniques were used. According to achieved results, the level of business intelligence exceeds the allowable amount $(0.78$ for all parameters of the model).
\end{abstract}

Keywords: Human resource management practices effectiveness, Selection and staffing, Performance appraisal, compensation 


\section{Introduction}

New technologies are being developed at a staggering speed, so societies and market desperately seek to find a way to ensure its survival in this disorganized and agitated arena. Few companies do business in traditional way and to keep up with competitors one must be completely aware of the new rules of game, so that one day he dictates his own rules. In such circumstances, the success of organizations in economic, cultural, social and governmental interactions is due to competence and effectiveness of human resources and in fact human resources are the major assistance in achieving organizational goals. So only if Human Resource Management assigns human resources effectively in the organization, it can help the organization achieve its objectives.

In 1930, Hawthorn studies led managers and employers to pay more attention to diverse needs of employees and since then the personnel units under titles such as staffing department, personnel department, department of welfare, etc. played a more active role in organizations [11]. Human resource management considers human being as a critical and outstanding factor for the survival, growth, competition and excellence of the organization. According to the research findings, a comprehensive human resource management system improves organizational performance. While boosts organizations capabilities, it keeps records, and as it's been said it plays a fundamental role in continuous competitive advantage [13].

Nowadays, regarding the growing importance of the human factor in organizations and more managerial concerns about this issue, personnel department units are highly crucial and often are working as a part of human resource management in organizations. Human Resource Management is the use of human resources for organizations purposes and includes activities such as staffing and recruiting, training, salaries and wages and organizational relationships. In fact human resource management as a professional obligation in organizations is responsible for functions and responsibilities far beyond staffing, personnel and welfare, and that's why administrators of these departments are elected from skilled and educated managers of organization [11].

The emergence of human resource development was a major shift from developing human resources focusing on individual learning towards a focus on the coordination between the HRD process, organizational strategy and goals. Due to the change in business environment, human resources management needs to be changed as well. Considering the necessity of responding to changes, environment forecasting and effective decision making about the future, human resources management must change. In recent years many researchers in the field of human resource development like Custer (2001), Garavan (1991), Ulrich (1997) and others have recommended the need for a clear link between human resource development and organizational goals and strategies. The future is unpredictable and it is difficult to determine what will happen. Thus flexibility and acquiring sufficient knowledge to respond to this kind of uncertainty is important. 


\section{2- Theoretical Foundations}

\section{2 -1- Models of Human Resource Management}

Harrell and Tezafrier introduced six groups of initiatives as the strategic and universal initiatives in human resources. This includes recruitment, selection, compensation, employee involvement, internal labor market and training [17]. Lussier (2005) considers human resource management consisting of four procedures: HR planning, staffing and recruiting, maintaining and flourishing employees [14]. Schuler and Jackson (2007) classified human resource management initiatives in planning, staffing, assessment, compensation, training and development [18]. Decenzo and Robbins (1998) also regarded human resource management consisting of recruiting, development, motivation and retention of human resources [7].

For designing a conceptual research model, first we performed studies on the effectiveness models of HRM practices like the model of human resources cycle, Wilson, Yorks (2005) [20]; the model of human resources, Gary Dessler (2003) [8]; human resource management model, Guest (1997) [12], the pattern of Dyer and Holder (1988) [9]; Harvard HRM Model, Beer et al (1984)[1]; human resource management model, Fombrun, Tichy and Devanna (1984)[10]. Then by integrating some model variables of effectiveness of HRM practices in the above mentioned researches according to the facts of statistical population under study, the conceptual model of research was designed.

\section{2 - The effectiveness dimensions in HRM initiatives}

* Training system: Training and improvement refers to planned efforts by which an organization facilitates the learning of job-related behavior for a part of employees. The overall objective of training is to achieve knowledge and skills which lead to increased personal skills in one or more areas of expertise and through this, required motivation background are provided and improved to do job properly. [15]

* Selection and staffing System: staffing and recruiting means the search and attracting a group of people which we can select eligible candidates with desired quality for vacations among them and accurate basis for this is a detailed description of job requirements through job analysis.

* Performance appraisal System: Performance appraisal of employees is the process of identifying, observing and assessing organizational performance. [5] This is the most widely accepted definition of evaluation. [3] Casive describes performance appraisal as the process of reviewing the strengths and weaknesses associated with the work of a person or a group in organization. [6]

* Compensation System: Compensation refers to any kind of reward which is a sign of gratitude for the people who get the job done. In the new approach to human resource management, compensation is not only via salary and bonus paid to employees. Also the quality of working life, including the indirect financial and non-financial benefits is concerned. [16] 


\section{Conceptual Model and Hypotheses}

Hypotheses that can be derived from the conceptual model of "human resource management practices effectiveness" are as follows:

H1: The level of human resource management practices effectiveness in terms of the "Training system" variable in Nir Pars Company is above average.

H2: The level of human resource management practices effectiveness in terms of the "Compensation system" variable in Nir Pars Company is above average.

H3: The level of human resource management practices effectiveness in terms of the "Performance appraisal" variable in Nir Pars Company is above average.

H4: The level of human resource management practices effectiveness in terms of the "selection and staffing system" variable in Nir Pars Company is above average.

The conceptual model including research hypotheses are shown in Figure 1.

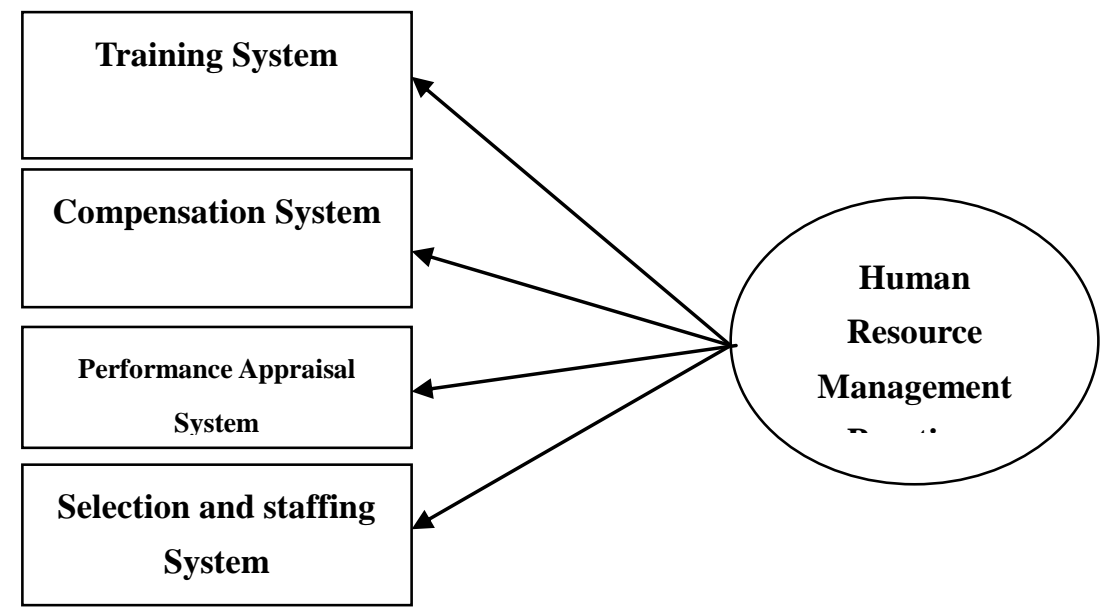

Figure 1: The proposed conceptual model of the research

\section{4 - Research Methodology}

The research method of the paper is "applied" in terms of objective and "descriptivecorrelation" in nature. To collect information about the literature review, library method including reading books, journals, and internet searching was used and we designed our own questionnaire to confirm or refute the research hypotheses. The research method in this paper is field study. The statistical population of the study consists of all experts and managers of different organizational levels in Nir Pars Company. After the identification of indicators, 225 questionnaires were distributed to a random sample of experts and executives of Nir Pars Company, 211 completed questionnaires were returned. Finally, using Exploratory Factor 
Analysis (EFA) and Structural Equation Modeling (SEM), the proposed conceptual model of research was analyzed. To analyze the obtained data in the quantitative section, we use descriptive statistics methods such as mean, frequency and inferential statistics and structural equation testing method. The aforementioned data will be analyzed using SPSS and LISREL statistical software.

\section{4-1- Validity and reliability of questionnaire}

Cronbach's alpha was used to assess the reliability of measuring instruments. The result of Cronbach's alpha of the 30 pre-test questionnaires was 0.961 . To examine the validity of the questionnaire, "content validity" and "structural validity" were used.

\section{Content validity}

Experts' judgment about how the questions of a test represent content and purpose of a program or content scope is used to determine the content validity of a test. For this purpose and to evaluate the research questionnaire, after establishing the basic framework, viewpoints of 16 persons (including 14 managers and experts in NIR Pars and 2 university teachers) were presented, put to the vote and approved.

\section{Structural validity}

Structural validity of a measuring instrument represents how it measures an attribute or structure which has the theoretical basis. Exploratory factor analysis and particularly factorial validity index were used to assess structural validity of questionnaire. In factor analysis the questions that were designed to evaluate an attribute or indicator should have common load factor and these factors need to be meaningful. So, all of the research questions that were designed using valid scientific questionnaires underwent exploratory factor analysis. Since the confirmatory factor analysis is analyzed in terms of a measurement model, and the fitness and validity of the model are discussed in its results, so the results of fitting measurement model are presented in what follows.

\section{4-2- statistical population and sample of research}

The statistical population of this research consists of 400 experts and managers at various levels of Nir Pars Company. Simple random sampling method was used. In this method sample size is obtained using Cochran's formula [4].

$$
\mathrm{n}=\frac{N \times \mathrm{Z}^{2} \alpha / 2 \times \sigma^{2}}{\mathrm{Z}^{2} \alpha / 2 \times \sigma^{2}+(\mathrm{N}-1) \times \varepsilon^{2}}
$$

In this formula, $\delta$ is the primary sample standard deviation for the entire questionnaire, $\varepsilon$ is the amount of allowable error, $Z=0.05$ is the unit normal variable corresponding to confidence level of $95 \%$; $\left(\mathrm{Z}_{\alpha / 2}=1.96\right)$ and statistical population $\mathrm{N}$ is 400 . 


$$
\mathrm{n}=\frac{N \times Z^{2} \alpha / 2 \times \sigma^{2}}{Z^{2} \alpha / 2 \times \sigma^{2}+(N-1) \times \varepsilon^{2}} \Rightarrow \mathrm{n}=\frac{400 \times(1.96)^{2} \times(0.57058)^{2}}{(1.96)^{2} \times(0.57058)^{2}+(400-1) \times(0.05)^{2}} \Rightarrow \mathrm{n}=224.62 \sim 225
$$

Given that the statistical population of this research is 400, according to Morgan table (1969) the desired sample size is 196. And Given that estimated standard deviation of the pilot sample ( $n=30$ ) equals 0.57058; and the other hand, due to the size of staff population based on Cochran's formula, sample size is at least 225 questionnaire. In this regard, 225 randomly selected questionnaires were distributed in the statistical population. Finally, after three stages of follow-ups (face to face, phone and email) 217 questionnaires were returned, which only 211 of them were completed.

\section{5- Research results}

\section{5-1- Data Analysis}

Inferential statistical techniques, especially exploratory factor analysis and confirmatory factor analysis were used for data analysis. First a set of 33 items related to "human resource management practices effectiveness" are factored using factor analysis. These outputs can be used for confirmatory factor analysis. In fact during the exploratory factor analysis, items are classified by the appropriate style. Then this factorization during the confirmatory factor analysis can be approved or rejected in structural equation modeling technique. The exploratory factor analysis was done by SPSS 19 and the confirmatory factor analysis by LISREL 8.8. The outputs of exploratory factor analysis and structural equation modeling will be presented.

\section{5-2- Data Analysis Using factor analysis}

Factor analysis tries to identify the underlying variables or factors to explain the pattern of correlations between observed variables. Factor analysis can be divided into two types of Exploratory and confirmatory categories. To perform a factor analysis the following four major steps are essential: 1- Forming a matrix of correlation coefficients from all the variables used in the analysis and estimation of subscription, 2- Extracting factors from correlation matrix, 3-Factor selection and rotation, 4- Analyzing the results [19].

After a factor analysis of 33 item questionnaire, based on data collected from 211 questionnaires, the KMO test index is 0.952 , which is greater than 0.6 and indicates the adequacy of sample size. Also given that the sig value of Bartlett test is smaller than $5 \%$.

As shown in Table 1 in this case factors 1 through 4 have Eigen values greater than 1 and remained in the analysis. In fact, the table suggests that the questionnaire, together with 4 factors and total explained variance higher than $72.32 \%$, could assess the "human resource management practices effectiveness". This shows the appropriate construct validity of the questions. 
Table 1: The Total Variance Explained of "Human Resource Management Practices Effectiveness"

\begin{tabular}{|c|c|c|c|c|c|c|c|c|c|}
\hline \multirow{2}{*}{$\begin{array}{c}\text { Dimensions of } \\
\text { Human } \\
\text { Resource } \\
\text { Management } \\
\text { Practices } \\
\text { Effectiveness }\end{array}$} & \multicolumn{3}{|c|}{ Initial Eigen values } & \multicolumn{3}{|c|}{$\begin{array}{l}\text { Extraction Sums of } \\
\text { Squared Loadings }\end{array}$} & \multicolumn{3}{|c|}{$\begin{array}{l}\text { Rotation Sums of } \\
\text { Squared Loadings }\end{array}$} \\
\hline & Total & $\begin{array}{c}\% \text { of } \\
\text { Varianc } \\
\text { e }\end{array}$ & $\begin{array}{c}\text { Cumulati } \\
\text { ve } \%\end{array}$ & Total & $\begin{array}{c}\% \text { of } \\
\text { Varianc } \\
\text { e }\end{array}$ & $\begin{array}{c}\text { Cumulat } \\
\text { ve } \%\end{array}$ & Total & $\begin{array}{c}\% \text { of } \\
\text { Varianc } \\
\text { e }\end{array}$ & $\begin{array}{c}\text { Cumulati } \\
\text { ve } \%\end{array}$ \\
\hline $\begin{array}{l}\text { Selection and } \\
\text { staffing (SS) }\end{array}$ & 18.126 & 54.927 & 54.927 & 18.126 & 54.927 & 54.927 & 6.966 & 21.108 & 21.108 \\
\hline $\begin{array}{l}\text { Performance } \\
\text { appraisal(PA) }\end{array}$ & 2.739 & 8.299 & 63.226 & 2.739 & 8.299 & 63.226 & 6.516 & 19.745 & 40.853 \\
\hline Training (TR) & 1.795 & 5.438 & 68.665 & 1.795 & 5.438 & 68.665 & 5.316 & 16.109 & 56.962 \\
\hline $\begin{array}{c}\text { Compensation } \\
(\mathrm{COM})\end{array}$ & 1.208 & 3.659 & 72.324 & 1.208 & 3.659 & 72.324 & 5.069 & 15.362 & 72.324 \\
\hline
\end{tabular}

Extraction Method: Principal Component Analysis.

According to Table (1), the first factor, i.e. "selection and staffing system" explains $21.1 \%$; the second factor, "performance appraisal" about 19.74\%; the third factor, "training" about $16.1 \%$; and the fourth factor "compensation" about $15.36 \%$ variance of "human resource management practices effectiveness", which actually indicates the importance of factors in formation of the "human resource management practices effectiveness" structure. The rotated factor matrix of these fields will be presented which indicates what questions and at what factor load are related to these factors. Table (2) represents factorial rotation matrix. 
Table 2: Rotated component matrix a "Human Resource Management Practices Effectiveness"

\begin{tabular}{|c|c|c|c|c|}
\hline \multirow[b]{2}{*}{ variables } & \multicolumn{4}{|c|}{ component } \\
\hline & $\begin{array}{c}\text { Selection and } \\
\text { staffing (SS) }\end{array}$ & Training (TR) & $\begin{array}{l}\text { Performance } \\
\text { appraisal(PA) }\end{array}$ & $\begin{array}{c}\text { Compensation } \\
\text { (COM) }\end{array}$ \\
\hline TR1 & .345 & .702 & .252 & .189 \\
\hline TR2 & .213 & .713 & .245 & .285 \\
\hline TR3 & .276 & .768 & .155 & .272 \\
\hline TR4 & .246 & .668 & .421 & .216 \\
\hline TR5 & .194 & .704 & .276 & .241 \\
\hline TR6 & .229 & .690 & .361 & .258 \\
\hline TR7 & .292 & .713 & .184 & .258 \\
\hline TR8 & .303 & .678 & .336 & .244 \\
\hline TR9 & .259 & .692 & .346 & .237 \\
\hline SS1 & .695 & .160 & .353 & .241 \\
\hline $\mathrm{SS} 2$ & .641 & .240 & .379 & .298 \\
\hline SS3 & .582 & .338 & .414 & .250 \\
\hline SS4 & .702 & .275 & .151 & .127 \\
\hline SS5 & .734 & .142 & .165 & .093 \\
\hline SS6 & 699 & .201 & .305 & .236 \\
\hline SS7 & .658 & .247 & .317 & .085 \\
\hline SS8 & .855 & .207 & .129 & .104 \\
\hline SS9 & .810 & .218 & .164 & .165 \\
\hline SS10 & .828 & .240 & .035 & .175 \\
\hline PA1 & .377 & .228 & 677 & .272 \\
\hline PA2 & .325 & .367 & .671 & .337 \\
\hline PA3 & .283 & .301 & .632 & .306 \\
\hline PA4 & .259 & .422 & .708 & .230 \\
\hline PA5 & .229 & .355 & .671 & .282 \\
\hline PA6 & .517 & .279 & .526 & .223 \\
\hline PA7 & .295 & .449 & .674 & .169 \\
\hline PA8 & .219 & .463 & .657 & .322 \\
\hline COM1 & .205 & .224 & .139 & .790 \\
\hline COM2 & .148 & .323 & .266 & .741 \\
\hline COM3 & .184 & .162 & .169 & .860 \\
\hline
\end{tabular}




\begin{tabular}{|l|l|l|l|l|}
\hline \hline COM4 & .122 & .331 & .298 & .711 \\
\hline COM5 & .242 & .262 & .175 & .749 \\
\hline COM6 & .224 & .290 & .356 & .764 \\
\hline
\end{tabular}

Extraction Method: Principal Component Analysis.

Rotation Method: Varimax with Kaiser Normalization.

a. Rotation converged in 4 iterations.

According to Table 2, we can come to the conclusion that the factors affecting "human resource management practices effectiveness" are classified in 4 groups which examine "human resource management practices effectiveness" considering "total converted variance" of $72.324 \%$.

\section{5-3- Data Analysis by Structural Equation Modeling}

To examine the causal relationships between variables in a coherent form, lots of efforts have been made in the past decade. One of the promising methods in this field is structural equation modeling or multivariate analysis with latent variables. This method is also known as the causal model and Covariance structure analysis by Bentler in 1980.Through this method; one can test the acceptability of theoretical models in particular populations using correlation, non-experimental and experimental data.

Structural equation modeling is a very wide and powerful multivariate analysis technique from the multiple regressions category that allows the researcher to examine a series of regression equations simultaneously. This method is a comprehensive statistical approach for testing hypotheses about the relationships between observed and latent variables [2]. When the data obtained from the sample changes to covariance or correlation matrix and is defined by a set of regression equations, then the model can be analyzed using the relevant software's and test its fit for the population from which sample was extracted. This analysis provides estimations of the model parameters (path coefficients and error terms) and some indicators for goodness of fit. Parameter estimates and information about goodness of fit can be used for testing possible changes in the model and re-examining the theoretical model [19]. 
Figure 2: Standardized Solutions Model for "Human Resource Management Practices

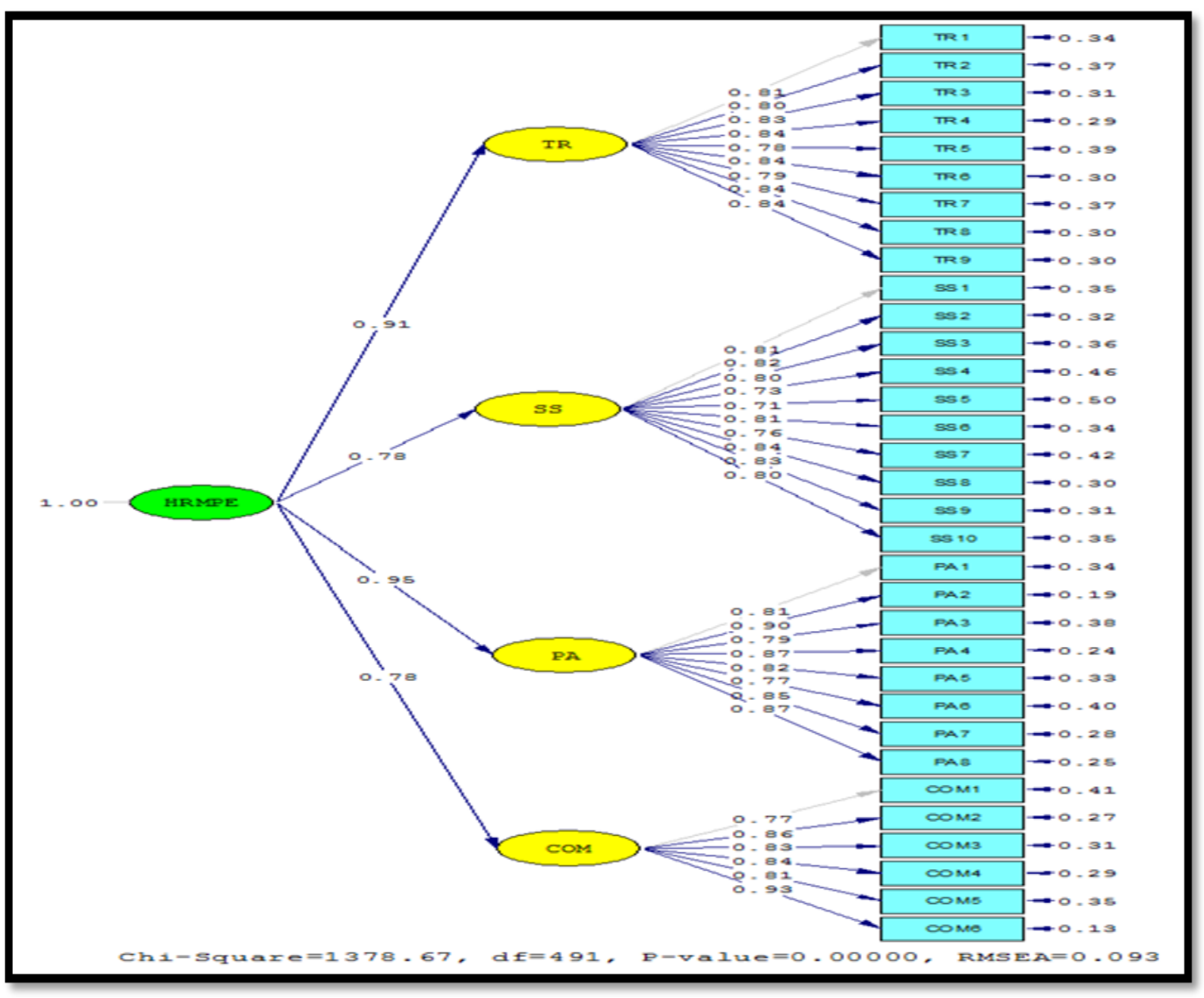

Effectiveness"

Figure (2) indicates that to what extents each of these factors explain the "human resource management practices effectiveness (HRMPE)" in the final model. The priority of these factors is as follows:

1. Performance appraisal (PA) with 0.95 path factor,

2. Training (TR) with 0.91 path factor,

3. Selection and staffing (SS) and Compensation (COM) both with 0.78 path factor. Also, based on figure (2), the following results for each aspect were obtained:

- The most important indicators in "Training" are "Proper planning and implementation of training courses" (with TR4 code), "Evaluating the Effectiveness of Training" (with TR6 code), "organization orientation toward empowerment and organizational learning" (with TR8 code) and "integration between the Human Resource Management strategies in the field of education system with other human resource management strategies" (with TR9 code) which all have a correlation coefficient of $84 \%$. 
- The most important indicators in "Selection and staffing (SS)" are "existence of equal opportunities for selection and staffing" (with SS8 code and) a correlation coefficient of $84 \%$ and "Following Meritocracy"(with SS9 code) with correlation coefficient of $83 \%$.

- The most important indicators in "Performance Appraisal (PA)" are "Using objective and subjective criteria in Performance appraisal" (with PA4 code) and "integration between the Human Resource Management strategies in the field of Performance appraisal system with other human resource management strategies" (with PA8 code) with correlation coefficient of $87 \%$.

- Finally the most important indicators in "Compensation (COM)" are "integration between the Human Resource Management strategies in the field of Compensation with other human resource management strategies" (with COM6 code) with correlation coefficient of $93 \%$ and "existence of a performance-based payment" (with COM2 code) with correlation coefficient of $86 \%$.

Figure (3) shows the model of meaningful number of "human resource management practices effectiveness".

Figure 3: T-Values for "Human Resource Management Practices Effectiveness"

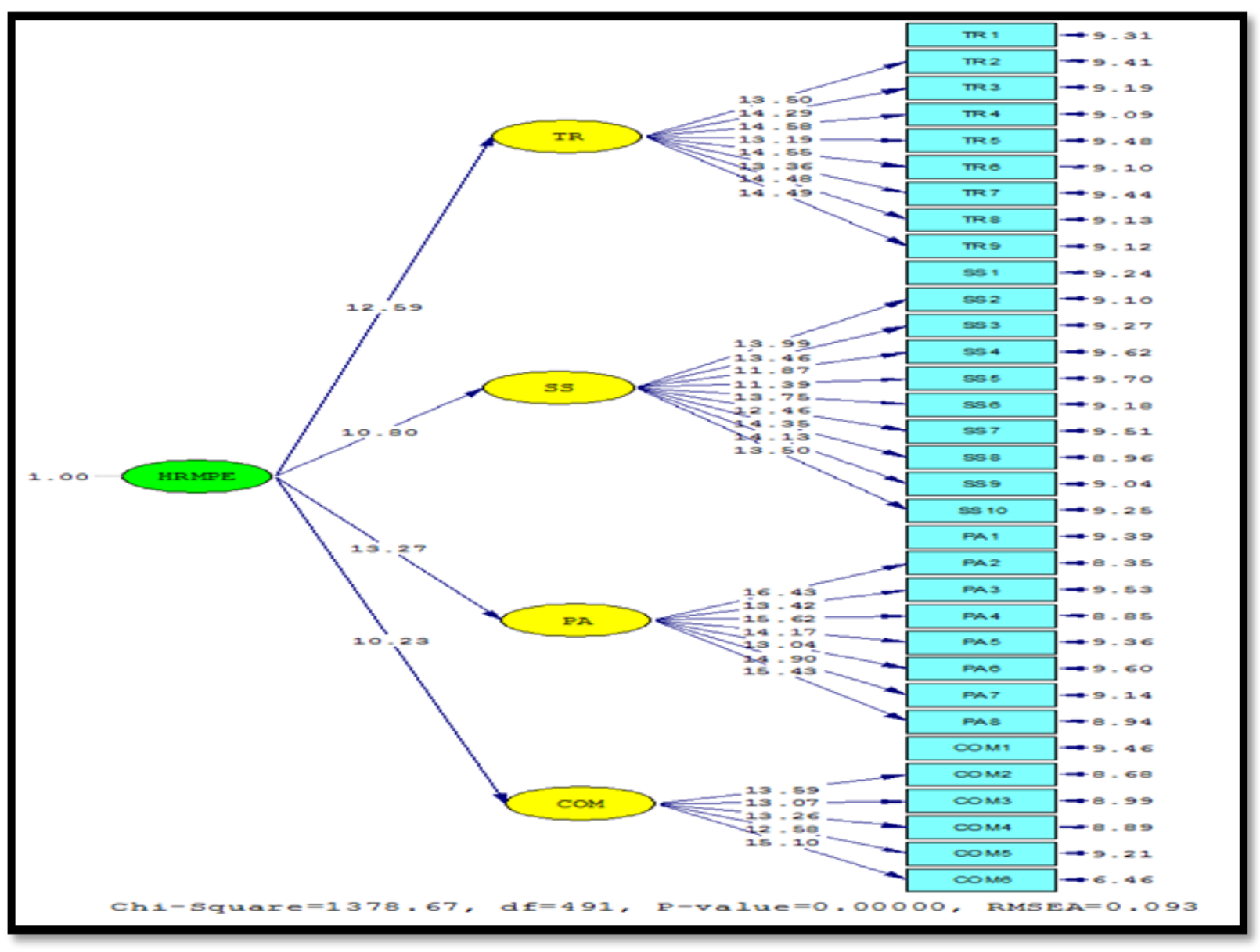


Indices of Model fitness indicate that the model is in a good condition considering appropriateness and fitness indices; because the ratio of chi-square to its degrees of freedom equals to 2.8079 which is less than allowed amount of 3 and the mean squared error is equal to 0.093 , which is less than allowed amount of 0.1 . So it does not need to be modified. Pvalue is also less than 0.05 . Optimum value of goodness of the fit indicator and its modified must be more than $90 \%$ so that goodness of the fit indicator in this model is 0.91 and its modified amount is equal to 0.85 which are appropriate.

\section{6 - Conclusion and Recommendations}

The purpose of this study is analyzing human resource management practices effectiveness and presenting a comprehensive model for Nir Pars Company of Tehran. Operational aspects of "human resource management practices effectiveness" are comprised of 33 items and four factors of "Organizational skills, business skills, IT skills, intellectual relationship skills, analytical skills and intellectual skills of competencies". Based on the conducted literature review and identification of its variables, four factors had the most important roles in "human resource management practices effectiveness". According to the analysis of results of SPSS and LISREL; the priority of the variables are "Selection and Staffing, Performance appraisal, Training and Compensation" respectively.

As shown in Figure 3, all significance numbers related to main aspects of the model are statistically significant; because their significance number is greater than 1.96. Consequently, the relevant hypothesis is approved. "Training" factor with the significance number (12.59), "Selecting and staffing" factor with the significance number (10.8), "Performance Appraisal" factor with significance number (13.27) and "Compensation" factor with significance number (10.23) have a positive and meaningful relation with "human resource management practices effectiveness".

In this research, based on the results of standard estimation model, practical suggestions for improving the "human resource management practices effectiveness" are applicable to Nir Pars Company:

1. To promote the level of "Training", proper planning and implementing training courses could be implemented and for improving this level, holding appropriate and job-oriented training courses is offered. According to the variety of training needs of employees, coordination of information with issues rose in training courses and pleasant and fun training courses in order to provoke motivation and attention is offered. It is also possible to consider the evaluation of effectiveness of teaching at different levels of the organization. By orienting towards empowerment and organizational learning, Organizations can improve level of training and by creating coherence between human resource management strategies in the field of education system with other strategies of human resource management improve the "human resource management practices effectiveness".

2. To promote the "Selection and Staffing" organizations can provide equal opportunities for selection and staffing and with respecting meritocracy at different levels of organizations 


\section{MIMacrothink}

"Selection and Staffing" could be enhanced. It is also possible to form recruiting committee and prepare guidelines for required conditions for specified vacations. By recruiting personnel in accordance with the terms specified by committee and by using experienced executives and experts for holding interviews and recruiting improves the "Selection and Staffing" and consequently promote "human resource management practices effectiveness".

3. In order to improve the "Performance Appraisal" in organizations setting objective and subjective criteria of Performance Appraisal, creating performance-based payment system, assessing the employee abilities and providing behavioral and performance records may lead to improvements in "human resource management practices effectiveness".

4. To improve "Compensation" organizations may create coherence between human resource management strategies in the field of compensation with other strategies of human resource management, the use of performance-based payment system, sharing employees in organizations' profits, using motivational factors and considering motivational dimensions and job security for the employees improve "Compensation" and consequently "human resource management practices effectiveness".

\section{Acknowledgement}

The authors are indebted of kind assistance of managers and employees of Nir Pars Company, respected university professors, and senior executives and managers. We would like to acknowledge all those who share their knowledge and guide us through the research.

\section{Corresponding Author}

\section{Davood ghiyasvand}

Corresponding Author, M.S. Candidate of Master Business Administration (MBA)

Isfahan Science and Research branch, Islamic Azad University, Isfahan, Iran

Email: d.ghiyasvand@gmail.com

Address: Science and Research Branch of Islamic Azad University, Shahroz Alley, Before the Crossroads Abshar, Abshar First Street, Khajoo Bridge, Isfahan, Iran.

Tel: +98- 912-2684809 - +98- 311-6624961

\section{Hadi Teimouri}

Assistant Professor, Management Department, University of Isfahan, Isfahan, Iran

Email: hadi_teimouri@yahoo.com

Address: College of Economy and Management, University of Isfahan, University Avenue, Azadi Square, Isfahan, Iran.

P.O.Box: 8174673441

Tel: +98- 913-1690601- +98-311-7935205 


\section{Reza Ansari}

Assistant Professor, Management Department, University of Isfahan, Isfahan, Iran

Email: rezaansar@yahoo.com

Address: College of Economy and Management, University of Isfahan, University Avenue, Azadi Square, Isfahan, Iran.

P.O.Box: 8174673441

Tel: +98-912-1467036 - +98-311-7935224

\section{References}

1. Beer M, Spector B, Lawrence P, Quinn MD, Walton R. 1984, Managing human assets, The Free Press, New York.

2. Brace N, Richard Kemp R, Snelgar R.2012. SPSS for Psychologists: Fifth Edition, Routledge; 5 editions, $488 \mathrm{p}$.

3. Caedy RL, Dobbins GH. 1994. Performance appraisal: alternative perspectives. Cincinnati, OH: South-Western Publishing.

4. Cochran, W. G. 1977. Sampling Techniques, Third Edition, New York: John Wiley \& Sons, Inc.

5. Carroll SJ, Schneier CE. 1982. Performance appraisal and review systems: the identification, mesurment and development of performance in organizations. Glenview, Il: Scott, foresman.V.2, 6: 217-246.

6. Cascio WF. 2006. Managing human resource: productivity.7th edition, Quality of Work Life, Profits, New York: McGraw-Hill, Irwin.

7. Decenzo DA, Robbins SP. 1998. Personnel human resource management. 3th edition, London: Printice -hell, $360 \mathrm{p}$.

8. Dessler G. 2003. Human Resource Management. Publisher: Prentice-hall of India.

9. Dyer L, Holder G. 1988. A strategic perspective of human resource management. In human resource management: evolving roles and responsibilities. L. Dyer (Ed.), Washington, DC: BNA.

10. Fombrun C, Tichy N, Devanna M. 1984. (eds) Strategic human resource management, John Wiley, New York, 3-18.

11. Fulmer RM. 1987. The new management. 4th edition, Atlanta: IBIA, Inc, 169 p.

12. Guest D. 1997. Humman resource management and performance, a review of the research agenda. The International Journal of Human Resource Management, V.8, 3: 263-276.

13. Lado A, Wilson MC. 1994. Human Resource Systems and Sustained Competitive Advantage: A Competency-Based Perspective. The Academy of Management Review , V.19, 4: 699-727.

14. Lussier R. 2005. Human relations in organizations: applications and skill-building. 6th edition, Mcgraw-Hill Irwin, 661p.

15. Mello JA. 2002. Strategic human resource management. 2th edition, Ohio: SouthWestern. 694 p.

16. Mondy RW, Robert MN, Shane RP. 2002. Human resource management. 8th US edition, Upper Saddle River, N.J. Prentice-Hall, 581p. 


\section{Macrothink

17. Pfeffer J. 1994. Competitive advantage through people. Harvard Business School Press, Boston,MA.

18. Schuler S, Jackson SE. 2007. Strategic human resource management: a reader, London: Blackwell Publishers.

19. Schumacker R. E, Lomax R. G. A .2010. Beginner's Guide to Structural Equation Modeling, Routledge; 3th edn, $536 \mathrm{p}$.

20. Yorks L. 2005. Strategic human resource development, Mason, OH: Thompson SouthWestern, $303 \mathrm{p}$. 